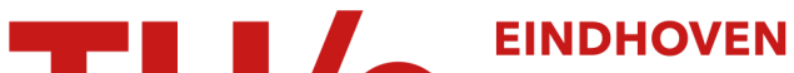 UNIVERSITY OF TECHNOLOGY
}

\section{A capacitor cross-coupled common-gate low-noise amplifier}

\section{Citation for published version (APA):}

Zhuo, W., Li, X., Shekhar, S., Embabi, S. H. K., Pineda de Gyvez, J., Allstot, D. J., \& Sanchez-Sinencio, E. (2005). A capacitor cross-coupled common-gate low-noise amplifier. IEEE Transactions on Circuits and Systems II: Express Briefs, 52(12), 875-879. https://doi.org/10.1109/TCSII.2005.853966

DOI:

10.1109/TCSII.2005.853966

Document status and date:

Published: 01/01/2005

\section{Document Version:}

Publisher's PDF, also known as Version of Record (includes final page, issue and volume numbers)

\section{Please check the document version of this publication:}

- A submitted manuscript is the version of the article upon submission and before peer-review. There can be important differences between the submitted version and the official published version of record. People interested in the research are advised to contact the author for the final version of the publication, or visit the $\mathrm{DOI}$ to the publisher's website.

- The final author version and the galley proof are versions of the publication after peer review.

- The final published version features the final layout of the paper including the volume, issue and page numbers.

Link to publication

\section{General rights}

Copyright and moral rights for the publications made accessible in the public portal are retained by the authors and/or other copyright owners and it is a condition of accessing publications that users recognise and abide by the legal requirements associated with these rights.

- Users may download and print one copy of any publication from the public portal for the purpose of private study or research.

- You may not further distribute the material or use it for any profit-making activity or commercial gain

- You may freely distribute the URL identifying the publication in the public portal.

If the publication is distributed under the terms of Article 25fa of the Dutch Copyright Act, indicated by the "Taverne" license above, please follow below link for the End User Agreement:

www.tue.nl/taverne

Take down policy

If you believe that this document breaches copyright please contact us at:

openaccess@tue.nl

providing details and we will investigate your claim. 


\title{
A Capacitor Cross-Coupled Common-Gate Low-Noise Amplifier
}

\author{
W. Zhuo, X. Li, S. Shekhar, S. H. K. Embabi, J. Pineda de Gyvez, D. J. Allstot, and E. Sanchez-Sinencio
}

\begin{abstract}
The conventional common-gate low-noise amplifier (CGLNA) exhibits a relatively high noise figure (NF) at low operating frequencies relative to the MOSFET $f_{T}$, which has limited its adoption notwithstanding its superior linearity, input matching, and stability compared to the inductively degenerated common-source LNA (CSLNA). A capacitor cross-coupled $g_{m}$-boosting scheme is described that improves the NF and retains the advantages of the CGLNA topology. The technique also enables a significant reduction in current consumption. A fully integrated capacitor cross-coupled CGLNA implemented in 180-nm CMOS validates the $g_{m}$-boosting technique. It achieves a measured NF of $3.0 \mathrm{~dB}$ at $6.0 \mathrm{GHz}$ and consumes only $3.6 \mathrm{~mA}$ from $1.8 \mathrm{~V}$; the measured input-referred third-order intercept (IIP3) value is $11.4 \mathrm{dBm}$. The capacitor cross-coupled $g_{m}$-boosted CGLNA is attractive for low-power fully integrated applications in fine-line CMOS technologies.
\end{abstract}

Index Terms-Common-gate amplifier, low-noise amplifier (LNA), noise figure (NF), RF integrated circuits.

\section{INTRODUCTION}

$\mathbf{W}$ ITH power consumption increasingly becoming a controlling factor in CMOS receiver design, the development of low power RF circuit techniques is necessarily generating considerable attention. The first on-chip active stage of an RF receiver is usually a low-noise amplifier (LNA). The well-known Friis equation sets its two most important specifications-low noise factor and high gain [1]. The basic commonsource LNA (CSLNA) topology provides better noise performance than the conventional common-gate LNA (CGLNA) at low operating frequencies relative to the MOSFET $f_{T}$; however, lower noise figure (NF) is often achieved using higher power consumption or off-chip matching components. Hence, the CSLNA topology is sub-optimum in low-power fully integrated applications. Increasing RF operating frequencies motivate the need for circuit design techniques that improve the NF of CGLNA and preserve its linearity, stability and low power consumption advantages. The capacitor cross-coupled CGLNA (CCC-CGLNA) [2] described herein achieves these goals.

Manuscript received December 8, 2004; revised April 4, 2005. This paper was recommended by Associate Editor B. Zhao.

W. Zhuo and X. Li are with the Qualcomm Inc., San Diego, CA 92121 USA.

S. Shekhar and D. J. Allstot are with the University of Washington, Seattle, WA 98195 USA (allstot@ee.washington.edu).

S. H. K. Embabi is with the SiRiFiC Wireless Corp., Richardson, TX 75080 USA.

J. Pineda de Gyvez is with the Philips Research Labs, 5656 AA Eindhoven, The Netherlands.

E. Sanchez-Sinencio is with the Texas A\&M University, College Station, TX 77843 USA

Digital Object Identifier 10.1109/TCSII.2005.853966

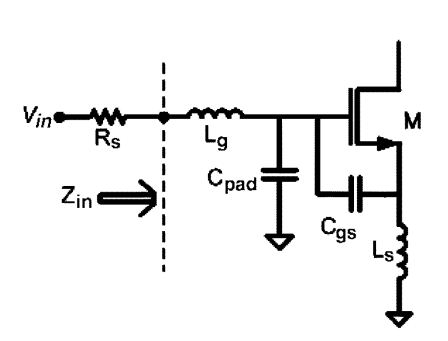

(a)

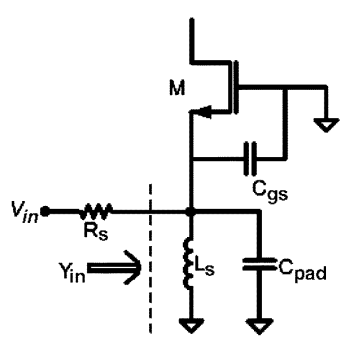

(b)
Fig. 1. Basic LNA stages. (a) CSLNA. (b) CGLNA.

Section II briefly compares the conventional CSLNA and CGLNA topologies [3], and Section III describes the general $g_{m}$-boosting technique. The capacitor CCC-CGLNA topology [2] is described in Section IV, and design and measurement results are presented in Section V.

\section{CSLNA VERSUS CGLNA TOPOLOGIES}

The critical benchmarks for characterizing the performance of an LNA are gain, NF, power consumption, reverse isolation, stability, linearity, ease of input matching and matching accuracy usually relative to $50 \Omega$.

The currently popular CSLNA topology [Fig. 1(a)] uses inductive degeneration to match the input impedance at resonance $\left(\omega_{T} L_{s}\right)$ to $50 \Omega$ [4]. Its input impedance can be expressed as

$$
Z_{\mathrm{in}, \mathrm{CSLNA}} \approx s L_{g}+\left(\frac{1}{s C_{\mathrm{pad}}}\right) / /\left(\omega_{T} L_{s}+s L_{s}+\frac{1}{s C_{g s}}\right)
$$

where $\omega_{T}=g_{m} / C_{g s}$ is the unity current gain frequency of the MOSFET. An effective series resonance created at the RF operating frequency leads to a noiseless resistive input match, which accounts for the superior noise performance of the CSLNA configuration. Its minimum noise factor including channel thermal noise and induced gate noise is given by

$$
F_{\min , \mathrm{CSLNA}}=1+\frac{\gamma}{\alpha}\left(\frac{\omega_{0}}{\omega_{T}}\right) \frac{2 \delta \alpha^{2}}{5 \gamma} Q_{\mathrm{opt}}
$$

where $Q_{\mathrm{opt}}=\sqrt{1+2|c| \sqrt{5 \gamma / \delta \alpha^{2}}+\left(5 \gamma / \delta \alpha^{2}\right)}$ [3], $\alpha, \gamma$, and $\delta$ are bias-dependent parameters [5], $c$ is the correlation coefficient between the gate noise and drain noise of the MOSFET, and $\omega_{0}$ is the operating frequency. 
In contrast to the CSLNA, a CGLNA [Fig. 1(b)] uses a parallel resonant network to match the input impedance at resonance $\left(1 / g_{m}\right)$ to $50 \Omega$. The overall input admittance is

$$
Y_{\mathrm{in}, \mathrm{CGLNA}} \approx g_{m}+s\left(C_{\mathrm{pad}}+C_{g s}\right)+\frac{1}{s L_{s}}
$$

where the body effect of the nMOS device has been neglected.

The noise factor including the channel noise and induced gate noise is

$$
\begin{aligned}
F_{\mathrm{CGLNA}}=1+\frac{4 k T \gamma g_{d 0} \Delta f}{\frac{4 k T}{R_{s} \Delta f}} & \left(\frac{1}{g_{m} R_{S}}\right)^{2} \\
& +\frac{4 k T \delta g_{g} \Delta f}{\frac{4 k T}{R_{s} \Delta f}}\left(\frac{1}{g_{m} R_{S}}\right)^{2} .
\end{aligned}
$$

With $g_{g}=\left(\omega C_{g s}\right)^{2} / 5 g_{d 0}$ and an input matching condition of $g_{m} R_{S} \approx 1$

$$
F_{\mathrm{CGLNA}}=1+\frac{\gamma}{\alpha}+\frac{\delta \alpha}{5}\left(\frac{\omega_{0}}{\omega_{T}}\right)^{2} \approx 1+\frac{\gamma}{\alpha}
$$

where the third term, accounting for the gate noise contribution, is usually negligible. Two important conclusions are drawn from the analysis and discussion above.

\section{A. Contribution of Gate Noise to NF}

The contribution from gate noise to the overall noise factor, $F_{\text {CGLNA }}$, is usually insignificant. For example, to a first order, it can be shown that even for an operating frequency $\omega_{0} / \omega_{T} \sim$ 0.5 , its contribution to the overall $F_{\mathrm{CGLNA}}$ is less than $5 \%$. In a CSLNA, however, the series $R L C$ tank enhances the gate noise contribution to $F_{\text {CSLNA }}$ by its $Q$ factor. If the contributions of gate and correlated noise sources are not considered properly in selecting the $Q$ value, a higher overall NF may result. Inaccurate and incomplete modeling of the gate and correlated noise sources usually renders this selection problematic in simulations; only measured results are dependable. In contrast, simulation of common-gate topologies does not suffer from large inaccuracies in gate noise modeling.

\section{B. Noise Factor at High Frequencies}

$F_{\text {CGLNA }}$ is weakly dependent on $\omega_{0} / \omega_{T}$ while $F_{\text {CSLNA }}$ is linear in $\omega_{0} / \omega_{T}$. Thus, the CGLNA stage has fundamentally superior noise performance for a higher operating frequency ratio, $\omega_{0} / \omega_{T}$. This point is further developed in Section IV.

One advantage of the series resonant tank at the CSLNA input is increased effective transconductance [3]. In fact, under a matched input condition, it can be shown that

$$
G_{m, \mathrm{CSLNA}}=g_{m} Q=\frac{1}{2 R_{S}}\left(\frac{\omega_{T}}{\omega_{0}}\right)=G_{m, \mathrm{CGLNA}}\left(\frac{\omega_{T}}{\omega_{0}}\right) .
$$

Thus, at low operating frequencies where $\omega_{T} / \omega_{0} \approx 5-10$, CSLNA has higher gain than CGLNA. However, a high Q input match also makes CSLNA more sensitive to process, voltage, and temperature (PVT) variations [6] and reduces its linearity. A CSLNA also exhibits inferior reverse isolation and stability
TABLE I

AdVAntages (+) AND Disadvantages (-) OF LNA Stages

\begin{tabular}{ccc}
\hline \hline Parameter & CSLNA & CGLNA \\
\hline Noise Factor & + & - \\
Effective G & + & \\
Parasitic & & + \\
Sensitivity & - & + \\
Input Matching & - & + \\
DC power & - & + \\
Reverse Isolation & - &
\end{tabular}

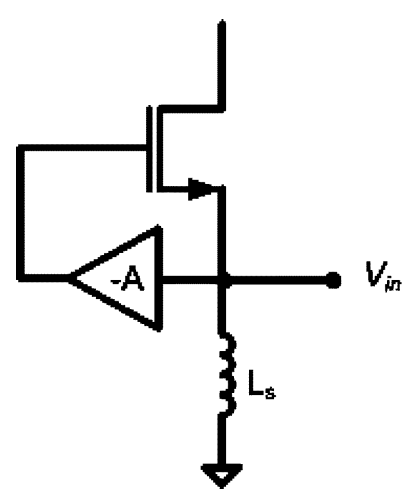

Fig. 2. Basic CGLNA stage with $g_{m}$-boosting feedback amplifier.

due to the Miller effect originating from the feedforward capacitor $C_{g d}$.

Table I compares the two basic LNA topologies. It clearly indicates that a CGLNA topology is more attractive if its effective $g_{m}$ is increased and its noise factor is decreased. A design technique for meeting these objectives is described in the next section.

\section{General $g_{m}$-Boosting Technique}

Ignoring the effects of gate noise, (5) can be expressed in greater detail as

$$
\begin{aligned}
F_{\mathrm{CGLNA}} & =1+\frac{4 k T \gamma g_{d 0} \Delta f}{\frac{4 k T}{R_{s} \Delta f}}\left(\frac{1}{g_{m} R_{S}}\right)^{2} \\
& =1+\frac{\gamma}{\alpha} \frac{g_{m}}{\frac{1}{R_{s}}}\left(\frac{1}{g_{m} R_{S}}\right)^{2} \\
& =1+\frac{\gamma}{\alpha} \frac{g_{m i}}{\frac{1}{R_{s}}}\left(\frac{1}{G_{m, \mathrm{eff}} R_{S}}\right)^{2}
\end{aligned}
$$

In (7), $g_{m i}$ represents the small-signal transconductance of the MOSFET and $G_{m \text {,eff }}$ is the effective transconductance of the active stage at the source terminal. Stated another way, $g_{m i}$ is related to channel thermal noise and $G_{m \text {,eff }}$ to input matching. In a conventional CGLNA, $G_{m, \text { eff }}=g_{m i}=1 / R_{s}$ constrains the lower bound on the noise factor to $(1+\gamma / \alpha)$. Note, however, that if $G_{m \text {,eff }}$ is boosted independently by modifying the input matching condition, $F_{\text {CGLNA }}$ is reduced. This is accomplished (Fig. 2) using a $g_{m}$-boosting scheme wherein inverting amplification, $A$, is introduced between the source and gate terminals so that $G_{m, \text { eff }}=(1+A) g_{m i}$ [3]. The resulting increase in the effective transconductance brings at least two significant improvements to the CGLNA topology. 


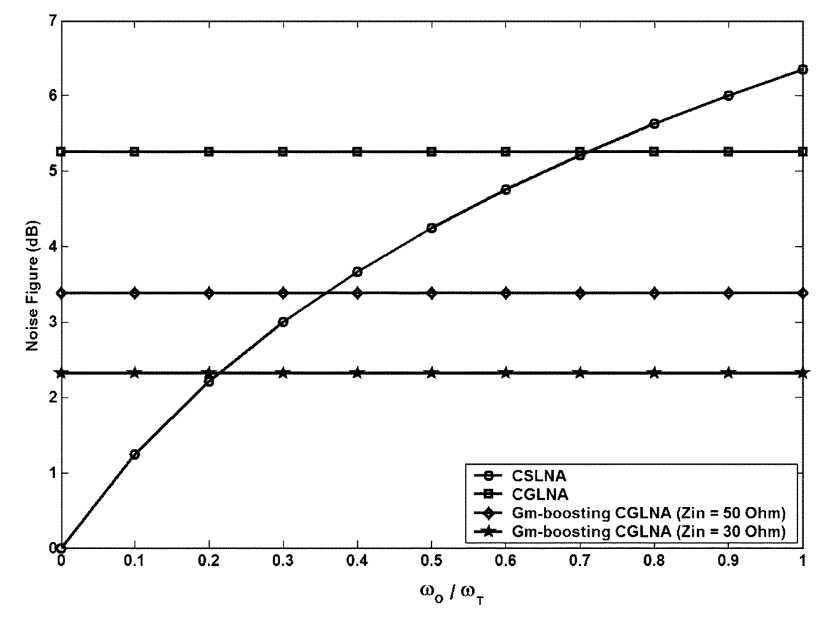

Fig. 3. Noise figure versus $\omega_{0} / \omega_{T}$ for various LNA topologies.

\section{A. Noise Factor}

The noise factor now becomes

$$
\begin{aligned}
F_{\text {CGLNA }, g_{m} \text {-boosting }} & =1+\frac{\gamma}{\alpha} \frac{g_{m i}}{\frac{1}{R_{s}}}\left(\frac{1}{(1+A) g_{m i} R_{S}}\right)^{2} \\
& =1+\frac{\gamma}{\alpha} \frac{1}{(1+A)}
\end{aligned}
$$

using the new input matching condition $1 / R_{s}=(1+A) g_{m i}$. Thus, $(F-1)$ in (8) is reduced by the factor $(1+A)$. Of course, this analysis assumes that the amplification stage itself does not contribute significant noise, which, in turn, motivates a passive implementation of $A$.

Fig. 3 plots the NF as a function of $\omega_{0} / \omega_{T}$ of the $g_{m}$-boosted CGLNA configuration. The noise factors of the conventional CSLNA and CGLNA circuits are also plotted for comparison. The $g_{m}$-boosted CGLNA stage exhibits superior noise performance compared to the CSLNA for $\omega_{0} / \omega_{T}>0.35$.

In many cases, an exact input match to $50 \Omega$ for the LNA is not absolutely necessary to meet practical specifications. For example, setting the input impedance $\left(1 /(1+A) g_{m i}\right)$ to $30 \Omega$ results in $S_{11} \approx-12 \mathrm{~dB}$, which means that less than $10 \%$ of the incident power is reflected [7]. The beauty of this tradeoff is that it allows $g_{m i}$ to be increased to further reduce the noise factor. As illustrated in Fig. 3, designing for a $30 \Omega$ input impedance allows the $g_{m}$-boosting CGLNA to outperform the CSLNA for $\omega_{0} / \omega_{T}>0.2$.

\section{B. Power Consumption}

The decoupled input matching condition of the $g_{m}$-boosted CGLNA also means that $g_{m i}=1 /(1+A) R_{s}$. Now the intrinsic transconductance is $(1+A)$ times less than that of the conventional CGLNA, which reduces the power consumption by the same factor.

\section{CAPACITOR CROSS-Coupled CGLNA}

One possible way to achieve passive inverting amplification in the $g_{m}$-boosted CGLNA is shown in Fig. 4 wherein a differential topology allows the differential active devices to be capacitor cross-coupled [2].

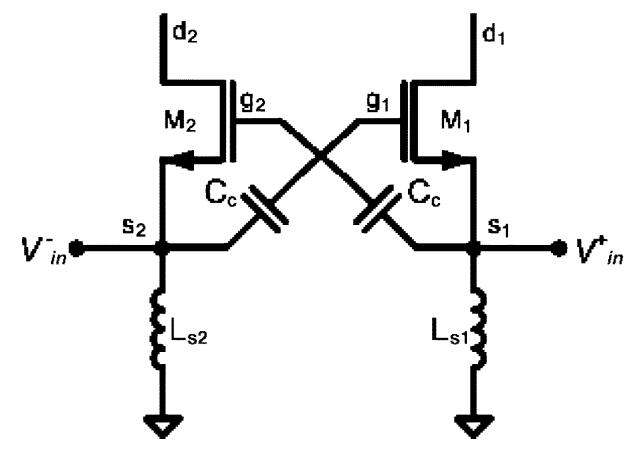

Fig. 4. Capacitor cross coupling in a differential CGLNA.

The inverting amplification value, $A$, for the topology of Fig. 4 is approximately given by the capacitor voltage division ratio

$$
A=\frac{C_{c}}{C_{c}+C_{g s}}=\frac{1}{1+\frac{C_{g s}}{C_{c}}}
$$

which, in turn, gives an effective transconductance of

$$
G_{m, \mathrm{eff}}=\left(\frac{C_{g s}+2 C_{c}}{C_{g s}+C_{c}}\right) g_{m i}
$$

and an approximate noise factor of

$$
F_{\mathrm{CGLNA}, \mathrm{CCC}} \approx 1+\frac{\gamma}{\alpha}\left(\frac{C_{g s}+C_{c}}{C_{g s}+2 C_{c}}\right) .
$$

Thus, $C_{C} \gg C_{g s}$ results in $A \approx 1$ and

$$
\begin{aligned}
G_{m, \mathrm{eff}} & \approx 2 g_{m i} \\
F_{\mathrm{CGLNA}, \mathrm{CCC}} & \approx 1+\frac{\gamma}{2 \alpha}
\end{aligned}
$$

Hence, the noise factor is reduced and the effective transconductance is increased with a concomitant decrease in power dissipation as described earlier.

\section{Design And Measurement Results}

Fig. 5 shows a CCC-CGLNA designed to operate at $6.0 \mathrm{GHz}$ in a $180-n m$ RF CMOS process. Differential transistors $M_{1}$ and $M_{2}$ are biased and sized for $1 / 2 g_{m i}=40 \Omega$. Although an input impedance of $30 \Omega$ enables higher gain and lower NF, this design is matched to $40 \Omega$ to maintain a safety margin on $S_{11}$ to account for possible modeling and simulation errors. Since the gates of the input transistors are not connected to an ac ground as in the conventional case, cascode devices $M_{3}$ and $M_{4}$ are added to improve the reverse isolation. The capacitors $\left(C_{C}\right)$ are $4.7 \mathrm{pF}$ and are used to cross couple $M_{1}$ and $M_{2}$. On-chip inductors $L_{s}$ are used to tune out the total capacitances at the source nodes including pad capacitances. A tapped-capacitor impedance match is used at the output to allow incorporation of the pad capacitances into $C_{p}$. The simulated $Q$ values of on-chip inductors $L_{s}$ and $L_{d}$ are approximately 10.

Fig. 6 shows measured $S_{11}$ and $S_{22}$ input and output matching characteristics, respectively. $S_{11}$ is less than -10 $\mathrm{dB}$ at $6.0 \mathrm{GHz}$ and above owing to the inherent broad-band input match of the common-gate topology. $S_{22}$ is $-7.3 \mathrm{~dB}$ at 


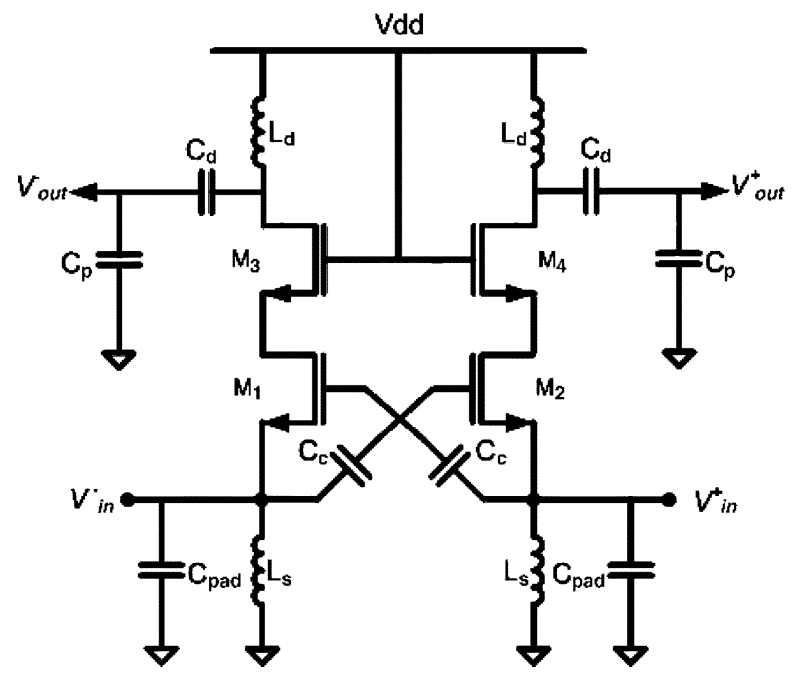

Fig. 5. Complete capacitor cross-coupled differential CGLNA stage.

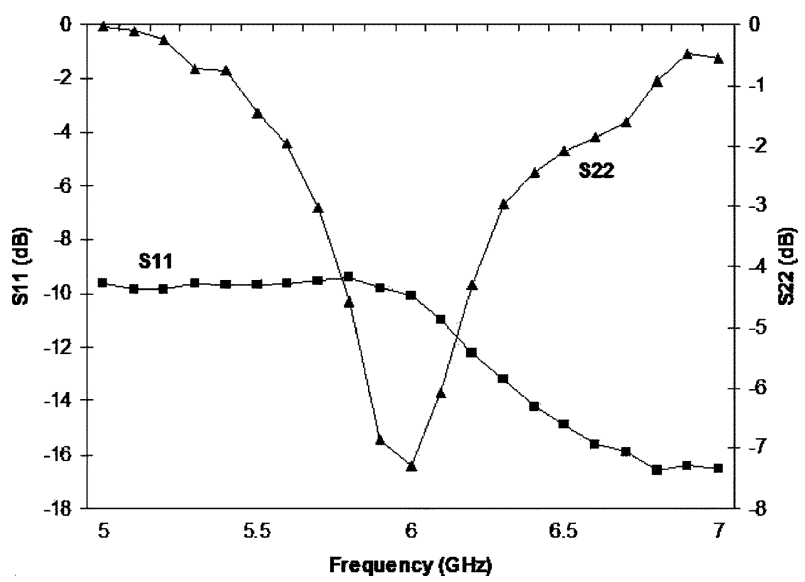

Fig. 6. Measured $S_{11}$ and $S_{22}$.

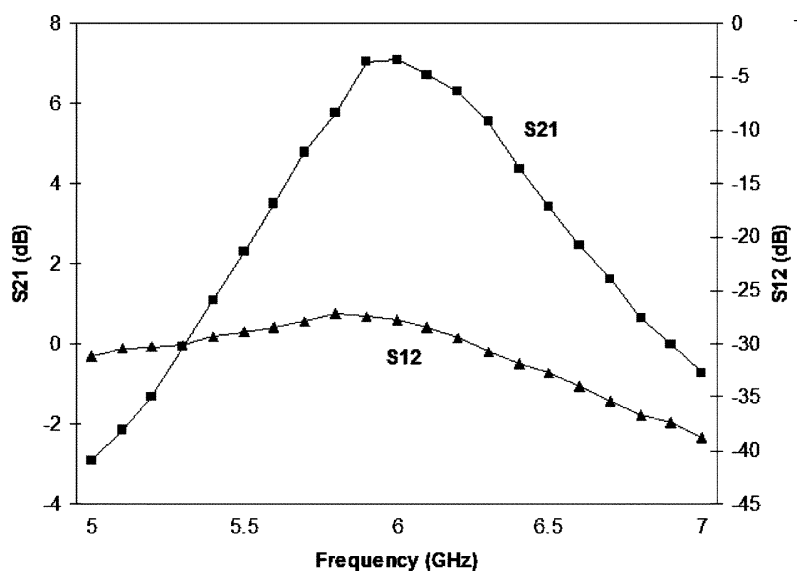

Fig. 7. Measured $S_{21}$ and $S_{12}$.

6.0 GHz. This is about $5 \mathrm{~dB}$ poorer than expected from the simulated results and is probably due to an overestimation of the $Q$ of $L_{d}$.

The measured power gain $S_{21}$ and reverse isolation $S_{12}$ plots are displayed in Fig. 7. The maximum power gain of $7.1 \mathrm{~dB}$ at $6.0 \mathrm{GHz}$ is lower (by $2 \mathrm{~dB}$ ) than expected from the simulation results due to imperfect output matching.

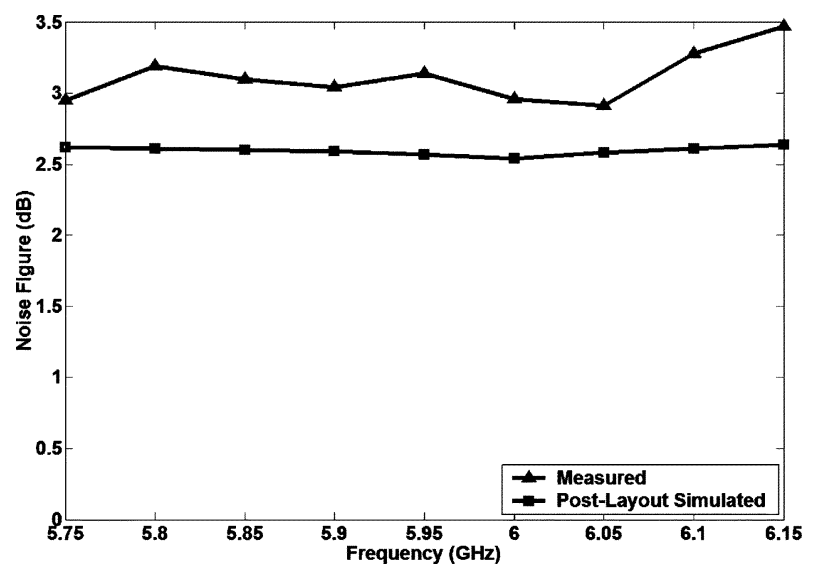

Fig. 8. Measured NF from 5.75-6.15 GHz.

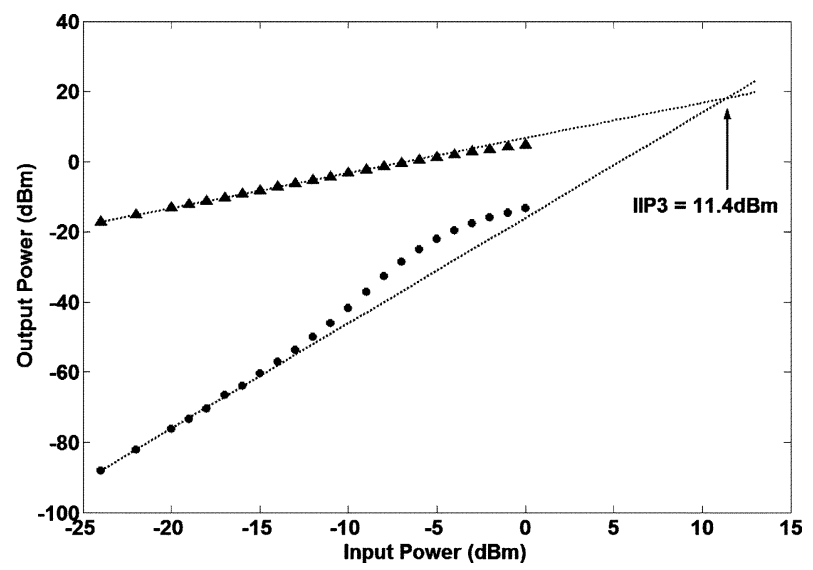

Fig. 9. Measured gain, IM3, and extrapolated IIP3 results.

A NF plot of the CCC-CGLNA is shown in Fig. 8. The fully integrated LNA achieves a NF of $2.97 \mathrm{~dB}$ at $6.0 \mathrm{GHz}$. This is an excellent NF value for a CGLNA topology, and it compares favorably with fully integrated CSLNA designs [8]. Note again that many common-source LNA circuits achieve excellent NFs at the cost of higher power consumption or the use of some off-chip matching components.

In order to verify the accuracy of the simulated NF value of a CGLNA, and to see the impact of induced gate noise to the overall $N F$, the measured value is compared to the simulated $N F$ in the same plot (Fig. 8). For fair comparison, the CCC-CGLNA is re-designed so as to have its simulated S-parameters identical to the measured results. The parasitic resistances and capacitances are also extracted from the layout and taken into the account in simulation. Still some discrepancies between the simulated and measured results are observed. They might be attributed to measurement inaccuracies $(\sim 0.25 \mathrm{~dB})$ and the effect of pads [9].

The third-order intercept point (IP3) is measured using a two-tone test with equal-amplitude 6.0- and 6.005-GHz signals. An excellent input-referred third-order intercept (IIP3) value of $11.4 \mathrm{dBm}$ is obtained as shown in Fig. 9. It is noted here that the linearity experiences degradation with the increase in the input power above $-12 \mathrm{dBm}$. A probable cause is the mixing of higher order terms into the IM3 product at larger input power levels. This, however, is not a cause for concern because the normal input power level at the input of the LNA is usually 


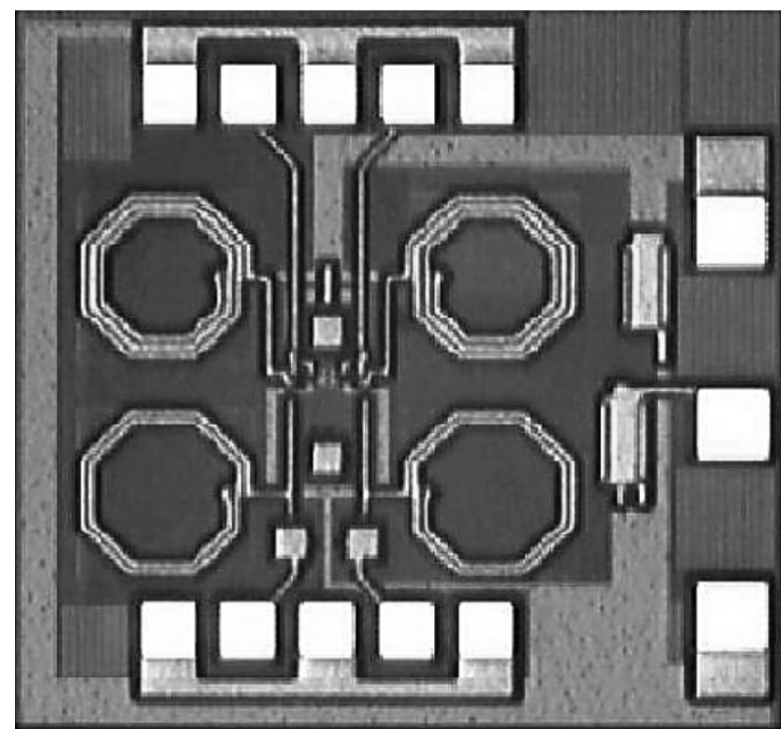

Fig. 10. Chip micrograph of the capacitor CCC-CGLNA.

TABLE II

MEASUREMENT RESULTS FOR CCC-CGLNA

\begin{tabular}{cc}
\hline \hline Parameter & Measured Results \\
\hline Frequency & $6.0 \mathrm{GHz}$ \\
Noise Figure & $3.0 \mathrm{~dB}$ \\
Gain $\left(S_{2 I}\right)$ & $7.1 \mathrm{~dB}$ \\
$I I P 3$ & $11.4 \mathrm{dBm}$ \\
DC current & $2 \times 1.8 \mathrm{~mA}$ \\
Power Supply & $1.8 \mathrm{~V}$ \\
Technology & $180 \mathrm{~nm} \mathrm{CMOS}$ \\
\hline
\end{tabular}

much smaller [10]. The capacitor cross-coupled $g_{m}$-boosted CGLNA draws $3.6 \mathrm{~mA}(2 \times 1.8 \mathrm{~mA})$ of dc bias current from a single $1.8-\mathrm{V}$ power supply. A chip micrograph is shown in Fig. 10. Implemented in a $180-\mathrm{nm} 48 \mathrm{GHz} f_{T}$ RF CMOS process, the total die area including pads is $975 \mu \mathrm{m} \times 975 \mu \mathrm{m}$. Table II summarizes the measured results.

\section{CONCLUSION}

A $g_{m}$-boosting technique to reduce the power consumption and improve the NF of a CGLNA is described. A capacitor cross-coupled LNA is presented as an implementation of the general technique. The fully integrated differential LNA consumes $3.6 \mathrm{~mA}$ from $1.8 \mathrm{~V}$ and attains a measured NF of $3.0 \mathrm{~dB}$ at $6.0 \mathrm{GHz}$. The proposed technique makes the CG topology attractive for low-power and high-frequency fully integrated designs.

\section{REFERENCES}

[1] H. T. Friis, "Noise figure of radio receivers," Proc. IRE, vol. 32, no. 7, pp. 419]-422, Jul. 1944.

[2] W. Zhuo, S. Embabi, J. Gyvez, and E. Sanchez-Sinencio, "Using capacitive cross-coupling technique in RF low-noise amplifiers and down-conversion mixer design," in Proc. Eur. Solid-State Circuits Conf., Sep. 2000, pp. 116-119.

[3] D. J. Allstot, X. Li, and S. Shekhar, "Design considerations for CMOS low-noise amplifiers," in Proc. IEEE Radio Frequency Integrated Circuits Symp., Jun. 2004, pp. 97-100.

[4] D. K. Shaeffer and T. H. Lee, "A 1.5-V, 1.5-GHz CMOS low-noise amplifier," IEEE J. Solid-State Circuits, vol. 32, no. 5, pp. 745-759, May 1997.

[5] Y. Cheng, C.-H. Chen, M. Matloubian, and M. J. Deen, "Highfrequency small-signal ac and noise modeling of MOSFETs for RF IC design," IEEE Trans. Electron Devices, vol. 49, no. 3, pp. 400-408, Mar. 2002.

[6] Q. Huang, F. Piazza, P. Orsatti, and T. Ohguro, "The impact of scaling down to deep submicron on CMOS RF circuits," IEEE J. Solid-State Circuits, vol. 33, no. 7, pp. 1023-1036, Jul. 1998.

[7] P. Leroux, J. Janssens, and M. Steyaert, "A 0.8 dB NF ESD-protected 9 mW CMOS LNA," in Proc. IEEE Int. Solid-State Circuits Conf., Feb. 2001, pp. 410-411.

[8] H. Chiu and S. Lu, "A $2.17 \mathrm{~dB} \mathrm{NF}, 5 \mathrm{GHz}$ band monolithic CMOS LNA with $10 \mathrm{~mW}$ DC power consumption," in Proc. Symp. VLSI Circuits, Jun. 2002, pp. 226-229.

[9] R. Fujimoto, K. Kojima, and S. Otaka, "A 7-GHz 1.8-dB NF CMOS low-noise amplifier," IEEE J. Solid-State Circuits, vol. 37, no. 7, pp. 852-856, Jul. 2002.

[10] Y.-S. Youn, J.-H. Chang, K.-J. Koh, Y.-J. Lee, and H.-K. Yu, "A $2 \mathrm{GHz} 16 \mathrm{dBm}$ IIP3 low-noise amplifier in 0.25 um CMOS technology," in Proc. IEEE Int. Solid-State Circuits Conf., Feb. 2003, pp. $452-453$. 